Journal of Engineering and Applied Sciences 14 (4): 1110-1121, 2019

ISSN: 1816-949X

(C) Medwell Journals, 2019

\title{
Application of Seismic Attribute and Spectral Decomposition: Example of Fluvial System During Miocene in Field A, Malay Basin
}

\author{
Muhammad Hazmi Abdul Malik and Lo Shyh Zung \\ Department of Petroleum Geosciences, Universiti Teknologi Petronas, \\ 32610 Bandar Seri Iskandar, Perak Darul Ridzuan, Malaysia
}

\begin{abstract}
Stratigraphic channels in field A Malay Basin including those with reservoir potential have been defined seismically. There were two exploration wells in field a however, the wells were abandoned due to low structural relief and volume were below economic criteria. This study discusses how seismic attribute and spectral decomposition give geomorphological information in different stratigraphic levels of Miocene age at Top F, H, I, Group I-50 and I-60. Facies analysis, seismic attribute, spectral decomposition and colour blending were implemented to identify hydrocarbon potential in stratigraphic traps and to enhance seismic resolution. Channel anomalies can be identified in seismic reflections characterized by high-amplitude events with chaotic reflections. Numerous sub-parallel reflection with high amplitude is observed in the upper formation. Several seismic attributes were used from the 3D seismic dataset to identify the geomorphologic features, potential reservoir variations, besides distribution and to extract the anomalies. Physical attributes which are related to amplitude, frequency, phase and their derivative were used including variance, instantaneous frequency, sweetness and spectral decomposition. Sweetness is the combination of lateral continuity and reflection strength. High reflection strength indicates maximum amplitude of the largest peak or through of real trace. This is especially, true when an event is a composite reflection. Amplitude attribute provides better spatial definition of events and bright spots could be enhanced. Instantaneous frequency shows composite frequency of the individual reflections contributing to a particular reflector. This composite is a useful correlation tool. Rapid changes in frequency are sometimes indicator of pinchouts such as oil/gas and water contacts. Low frequency anomalies are observed in zones below hydrocarbon reservoirs. Meanwhile, instantaneous phase is useful in stratigraphic analysis of certain sections because the sharp zero crossings that results may emphasize lateral discontinuities, pinchouts and angularities. The combination of attribute analysis and spectral decomposition aids the interpretation and identification of some channel patterns and channel distribution. Two methods of spectral decomposition are used Short Time Fourier Transform (STFT) and S-transform which focus on spatial and temporal range, respectively. Red Green Blue (RGB) colour blending represents different frequency ranges of low, mid and high frequency bands and display as a single image. This method reveals additional information such as depositional elements, anomaly identification, bed thickness, presence of fluids and help to resolve petrophysical heterogeneity. This study reveals that there are strong evidences of hydrocarbon potential in stratigraphic traps for further exploration within the study area.
\end{abstract}

$\underline{\text { Key words: Facies analysis, spectral decomposition, stratigraphic traps, instantaneous frequency, STFT, RGB }}$

\section{INTRODUCTION}

Field A is located on the Eastern flank of Malay Basin as shown in Fig. 1. Its depositional environment during Early Miocene was coastal plain with fluvial channels. During Early Miocene, there was a significant sea level fall that caused sediment supply rate to surpass subsidence rate (Thinh, 2014). Coastal plains were dominant depositional environment. Hence, the purpose of this study is to identify the deformation of structural geomorphology based on interpretation of 3D high-resolution seismic data covering about $267 \mathrm{~km}^{2}$. For better geological visualisation, several common techniques ave been done, including; imaging stratigraphy through different horizons, seismic interval attribute analysis and colour rendering.

A 3D post stack seismic data with dimension of $16.9 \mathrm{~km}$ length, $15.8 \mathrm{~km}$ width and $1.9 \mathrm{~km}$ depth was given as shown in Fig. 2. Based on a quick observation, a lot of channel patterns are clearly seen from the seismic section.

Corresponding Author: Muhammad Hazmi Abdul Malik, Department of Petroleum Geosciences, Universiti Teknologi Petronas, 32610 Bandar Seri Iskandar, Perak Darul Ridzuan, Malaysia 


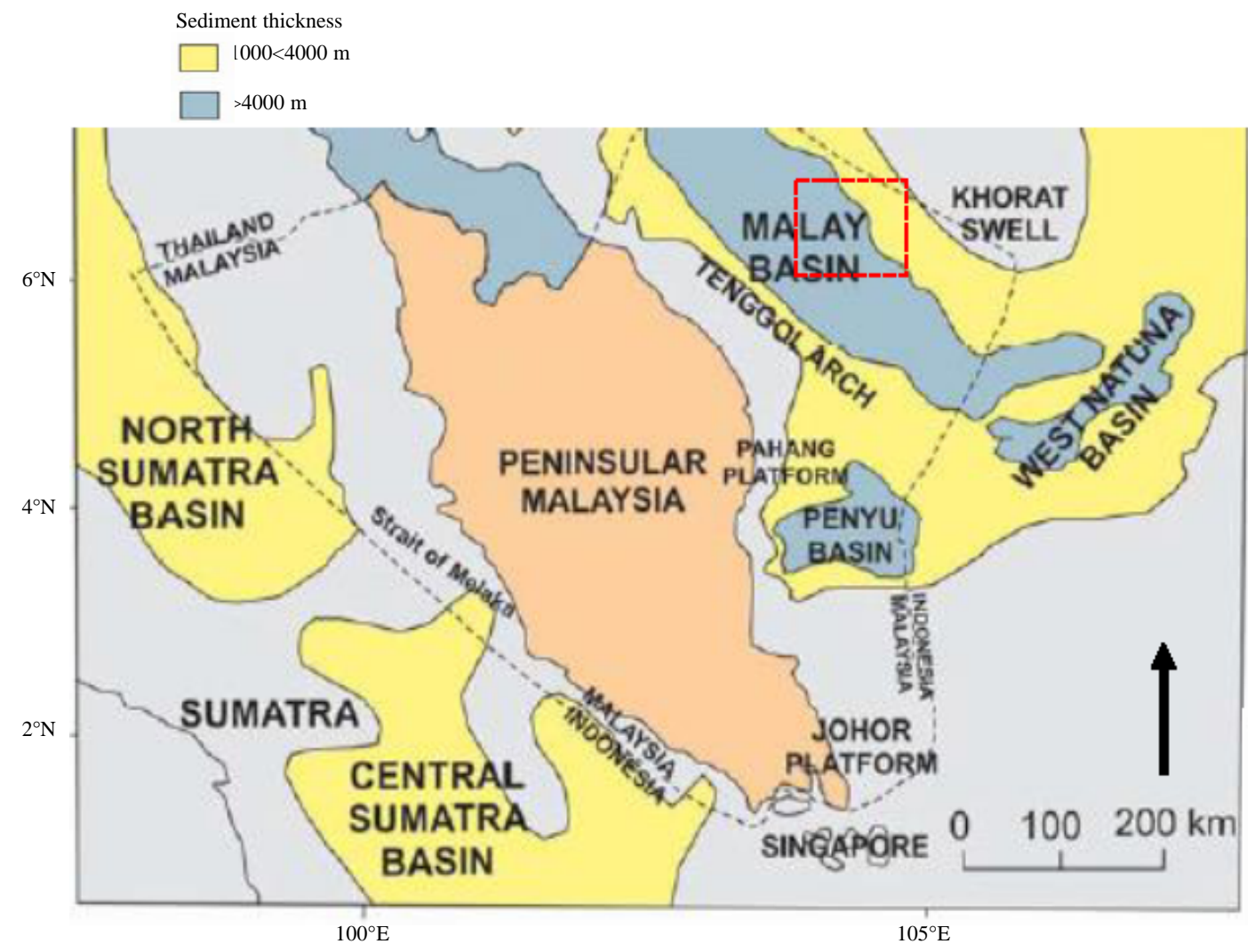

Fig. 1: Location of area of interest located at dashed rectangular line (Sulaiman et al., 2016)

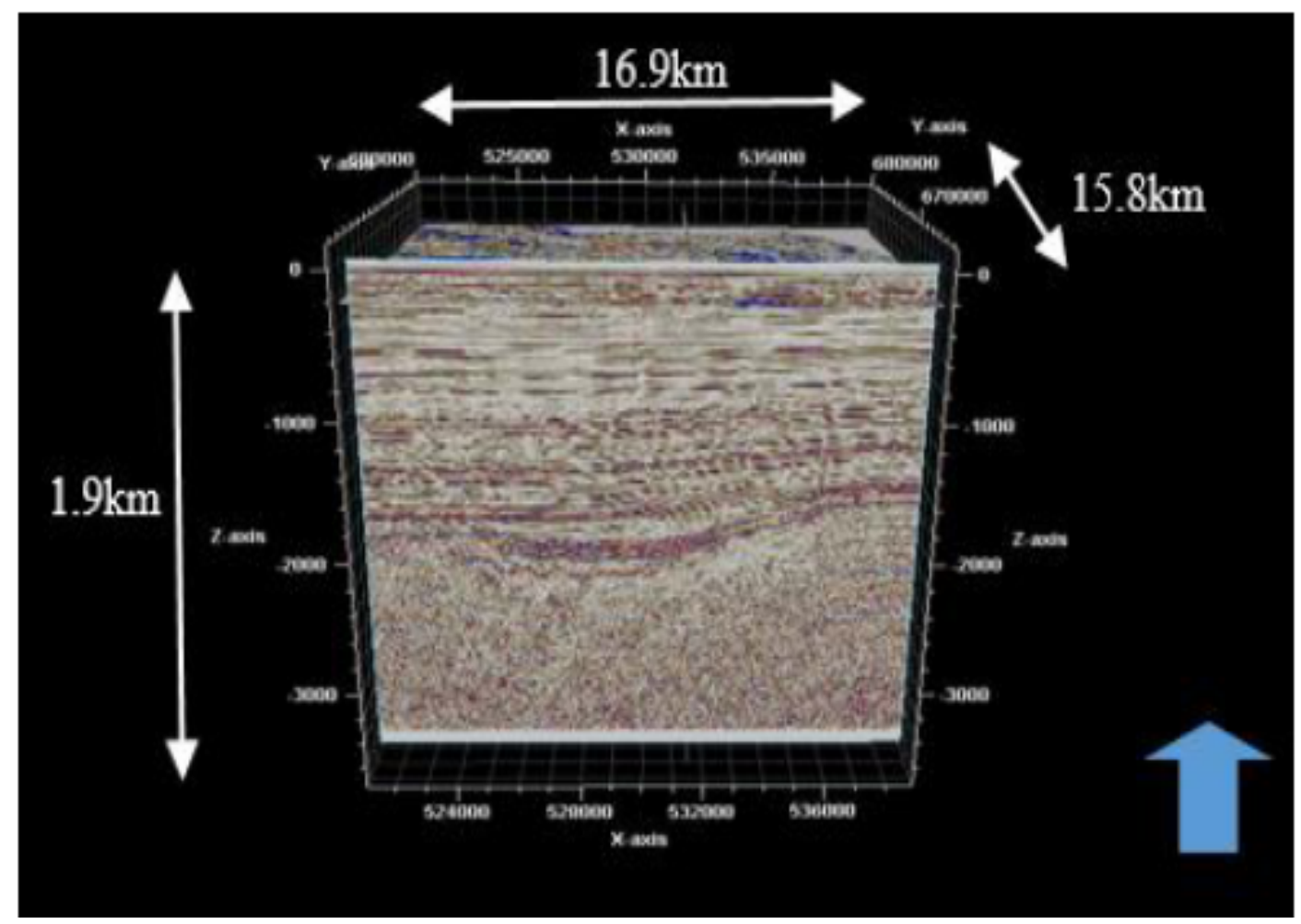

Fig. 2: 3D post-stack seismic data with dimension $267 \mathrm{~km}^{2}$ of field A supplied by Petronas 
Most of the production in Malay Basin came from structural traps and a few from stratigraphic trap. Exploration tools and software were used to better understand the geological setting to overcome the challenges of finding hydrocarbon in stratigraphic traps.

\section{Geological setting}

Regional geology of Malay Basin: Malay Basin is a productive hydrocarbon province, especially, at Cenozoic section with an area of $500 \mathrm{~km}$ long and $200 \mathrm{~km}$ wide. Many studies regarding regional geology and paleo-depositional environment have been conducted in the region. Three major tectonic events that led to the formation of the Malay Basin are extensions, thermal subsidence and compressions. Malay Basin begin to form as the result of Indian plate collision with Eurasia during Eocene. The initial synrift ( $\sim 50-45 \mathrm{Ma})$ events caused uplifting due to tectonic activity which affected depositional environment. During synrift phase, the rate of tectonic subsidence were faster than the rate deposition causing lacustrine formation to be laterally restricted (Thinh, 2014). Lithologies that filled synrift basins comprise boulders and basal conglomerate, volcanic ash and granitic.

Lake level started to rise during middle synrift ( 45-35 Ma) which allowed deposition of fluvial/alluvial plain at both sides of high areas. There were significant changes in depositional environment during middle Oligocene where there was rapid increase in lake level with a low sediment rate of supply which formed thick fine-grain lacustrine sediments. During this period, the rate of sedimentation exceeded subsidence rate that led to a significant fall in lake level. More channel systems developed and were deposited; increasing reservoir quality sand into the lakes that evolved into fluviodeltaic environment. Rapid fluvial sedimentation in coastal plain and lacustrine-dominated setting during the Oligocene (Tjia, 1994). 3D post-stack seismic data helps in visualizing the stratigraphic record according to selected stratigraphic markers. From the $3 \mathrm{D}$ seismic time slices, the author can easily identify multiple stacks of fluvial channels; topped by thinner floodplain fine sediments.

Progressive subsidence rates due to thermal cooling during late Oligocene created accommodation space filled with sandstones and mudstones. This early post-rift phase was dominated by complex sand-rich fluvial systems consisting of multiple channels as the lake level continued to decrease. Sedimentation was in extensive swamp, lower coastal plain and tidal environments from the earliest Miocene onward.

\section{MATERIALS AND METHODS}

Seismic analysis: Evolution of interpretation techniques together with availability of field data make it easier to analyse and interpret geological landforms. Combination between seismic geomorphology and seismic stratigraphy enables the interpreter to identify stratigraphic facies variability. Numerous techniques has been done throughout this study in order to extract stratigraphic information from 3D volume cube. Since, early 90's, new technologies enable a high resolution of seismic attribute which aided depositional architecture analysis (Sulaiman et al., 2016).

This study aims to determine the variation in geomorphologic feature in case of fluvial architecture within early to mid-miocene by using seismic attribute analysis and spectral decomposition. Besides that, interpretation from seismic sections and time slices also lead to identification of geomorphology. Amplitude strength, frequency and internal configuration patterns are three elements that influence seismic reflections in seismic sections.

Based on seismic 3D data analysis, several geomorphological features were identified at a few levels of deposition. Upon recognition of the presence of geomorphological features, 3D seismic cube time slices and horizon slices were generated from TWT $-964 \mathrm{msec}$ (Top F) till-1,450 msec (Group I-70). Altogether about seven channels with different patterns have been mapped throughout the seismic cube.

The time-slice seismic attributes are applied in order to enhance the anomalies once the features of interest are identified. Generation of seismic attributes will identify similar internal configurations of seismic including amplitude and frequency. Different attributes reveal different characteristics at the area of interest. In this study, variance attribute is used to measure the amount of dissimilarity between adjacent seismic traces. This discontinuity attribute is useful to highlight the subtle stratigraphic features in map view.

Instantaneous frequency shows the composite frequency of the individual reflection contributing to a particular reflector. This composite may be a useful as a correlation tool. Rapid changes in frequency are sometimes indicator of pinchouts and hydrocarbon and water contacts. Low frequency anomalies are observed in zones below hydrocarbon reservoirs.

Meanwhile, sweetness focusing on amplitude/reflection strength and horizon discontinuity which can be used to estimate net-to-gross ratio in reservoir targets. However, this attribute is not relevant when sand and shale have high differences in acoustic 


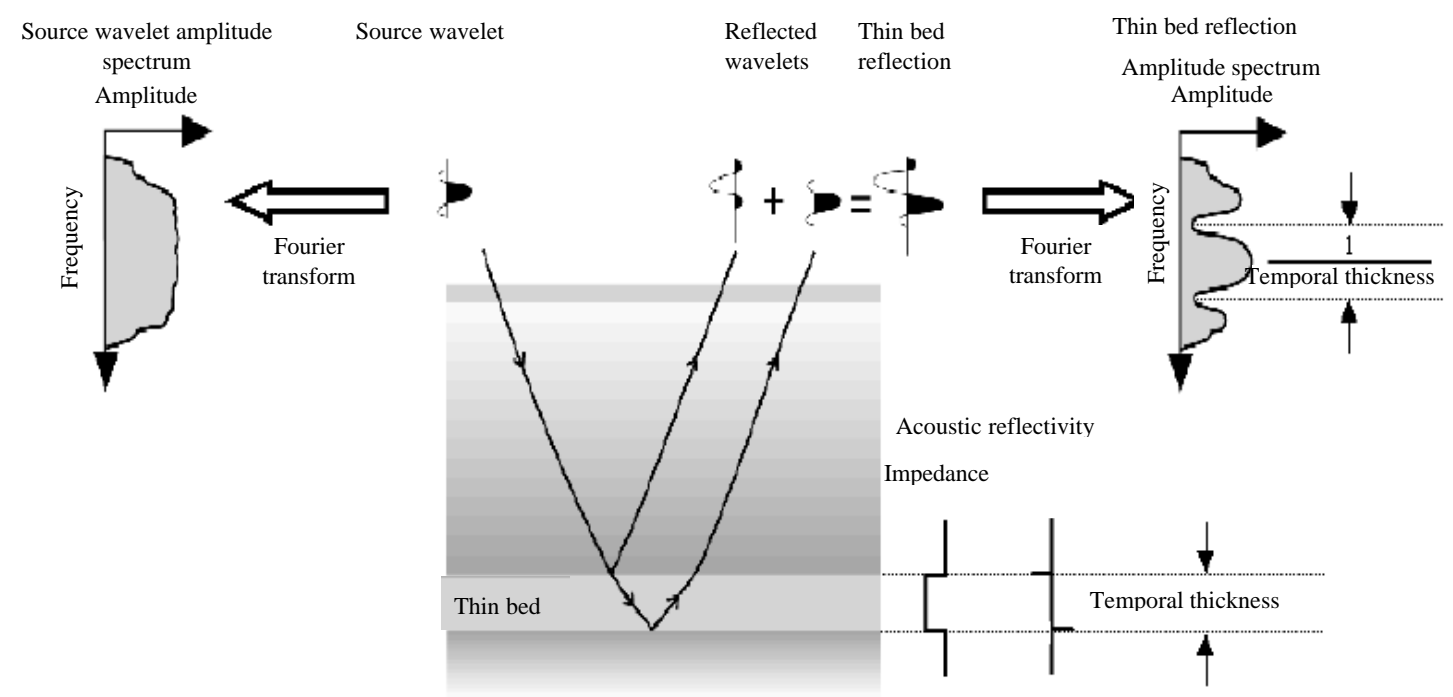

Fig. 3: Workflow of spectral decomposition to identify thin beds through analysis of the frequency spectrum

impedance. High sweetness shows presence of isolated sands as it responds to high amplitudes and low frequencies.

The variance attribute represents trace-to-trace variability in a certain sampled interval and it is calculated in three dimensions. Hence, the purpose function of variance is to interpret lateral changes in acoustic impedance. Discontinuities of seismic reflection give high coefficient while similar traces shows low variance coefficient. This is because channels and faults cause discontinuities in reflection and subsequently in the trace-to- trace variability; hence, they become detectable in 3D seismic volumes. Therefore, variance attributes can be seen as the lateral counterpart of RMS as variance is sensitive to vertical variations. Multi-attributes can be useful for geobody detection in seismic slices. It can reveal structural and stratigrapic information by combining all the details on independent seismic attribute.

Furthermore, reflection characteristics of seismic amplitude, reflection geometry and reflection continuity in seismic section are able to identify geomorphologic subtleties. Seismic amplitude represents reflection strength and can be useful for facies type, impedance contrast (for significant stratal surfaces), fluid content and heterogeneity of the formation. Reflection continuity reveals extent of depositional environments and lateral stratal continuity.

Spectral decomposition: Spectral decomposition is a method where transformation of seismic traces into a single seismic wavelet is achieved by altering the frequency components thus providing a high-resolution in seismic data which can be used for imaging and mapping the geological discontinuities and temporal bed thicknesses. Spectral decomposition works on different frequency bands which gives high resolution in seismic cube. The frequency bands correspond to certain size structures due to tuning effects.

The objective of spectral decomposition is to reveal the structural and geomorphological features at different seismic responses by varying the frequency bandwidth since lower frequencies image thicker beds while higher frequencies image thinner beds. As the seismic wave travels deeper, the seismic energy undergoes reflection, refraction or absorption process; seismic energy will be attenuated causing the frequency content to decrease with depth. In real case, the seismic trace responses from multiple subsurface layers and form a complex-tuned reflection which has a combination of all frequency domain expression. Therefore, it is difficult to predict a simple homogenous thin bed by using full frequency bandwidth. Figure 3 shows the simulation of seismic wave propagation through different type of rock formations.

In this study, only two spectral decomposition methods are used Short Time Fourier Transform (STFT) and S-transform. STFT has good approximation to real seismic traces/wavelets as it is based on Gaussian-tapered cosines and sines. Partyka et al. (1999) interpreted 3D seismic volumes by using tapered rectangular windowed cosine and sines wavelets. Meanwhile, Sinha et al. (2003) used STFT to study anomalous attenuation and tuning effects. The S-transform gives a better mechanism to 
decompose the signal wave from time domain to frequency domain. This method is a combination of STFT and continuous wavelet transform. In S-transform, both time and frequency were function in Gaussian window.

Red Green Blue (RGB) or colour blending is a combination of multi attributes according to colour schemes. RGB presents different frequency ranges of low $(20 \mathrm{~Hz})$, dominant $(40 \mathrm{~Hz})$ and high $(60 \mathrm{~Hz})$ frequency bands and displays as a single image. Basically, application of RGB blending is to blend spectral decomposition outputs such as iso-frequency response. This method reveals additional information such as depositional elements, anomaly identification, bed thickness, presence of fluids and helps to resolve petrophysical heterogeneity.

\section{RESULTS AND DISCUSSION}

Facies analysis: Changes in depositional environment is seen through vertical changes in time slices and horizon slices. Extraction of stratigraphic elements can be determined from anomalies shown in the seismic cube.

Figure 4 shows the seismic section from Group F till Group J. From quick facies analysis, Group F at $-841 \mathrm{msec}$, the seismic characterisation is moderate amplitude and poor lateral extent of seismic reflection (sub-parallel). The thickness between amplitude layering are quite close in Group F. It is interpreted that Group F formation consists of fine sediments such as claystones or shales interbedded with thin sandstones.

Group I seismic amplitude are weak (dull). This is probably caused by homogeneous formation or thick sand with minor shales. The continuity of seismic reflection is good compared to Group F. However, a sudden high in amplitude with good continuity can be observed in the middle of Group I which relates of coal. At least two anomalies can be identified like channel patterns with high amplitude in this seismic section. It might be a prospect if there is any stratigraphic trap within the levels as it is clearly seen in seismic section. Seismic resolution

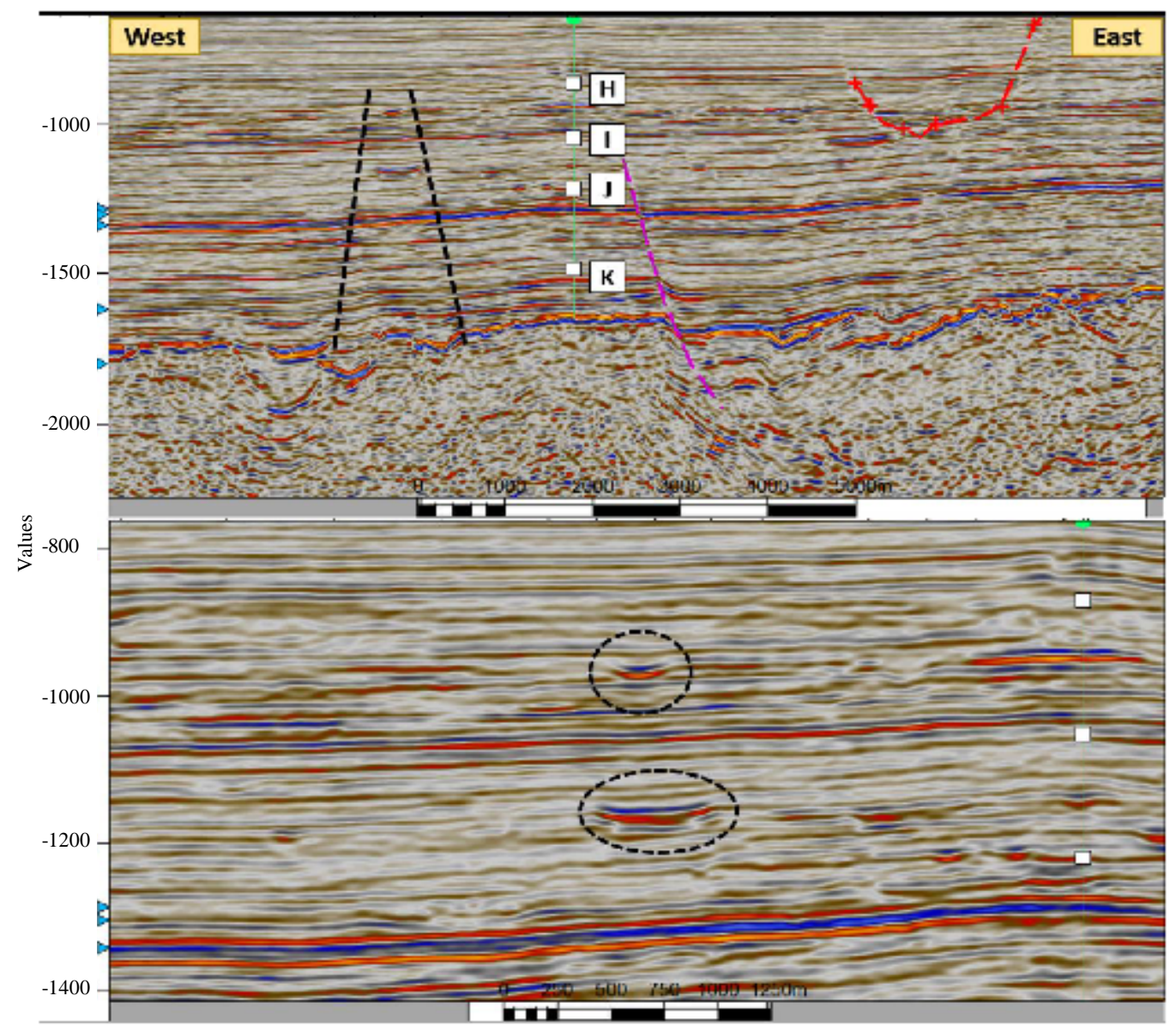

Fig. 4: Seismic section at Inline 3083 shows anomalies of lenticular bend nearby to A-2 well located at bottom F and Group I 


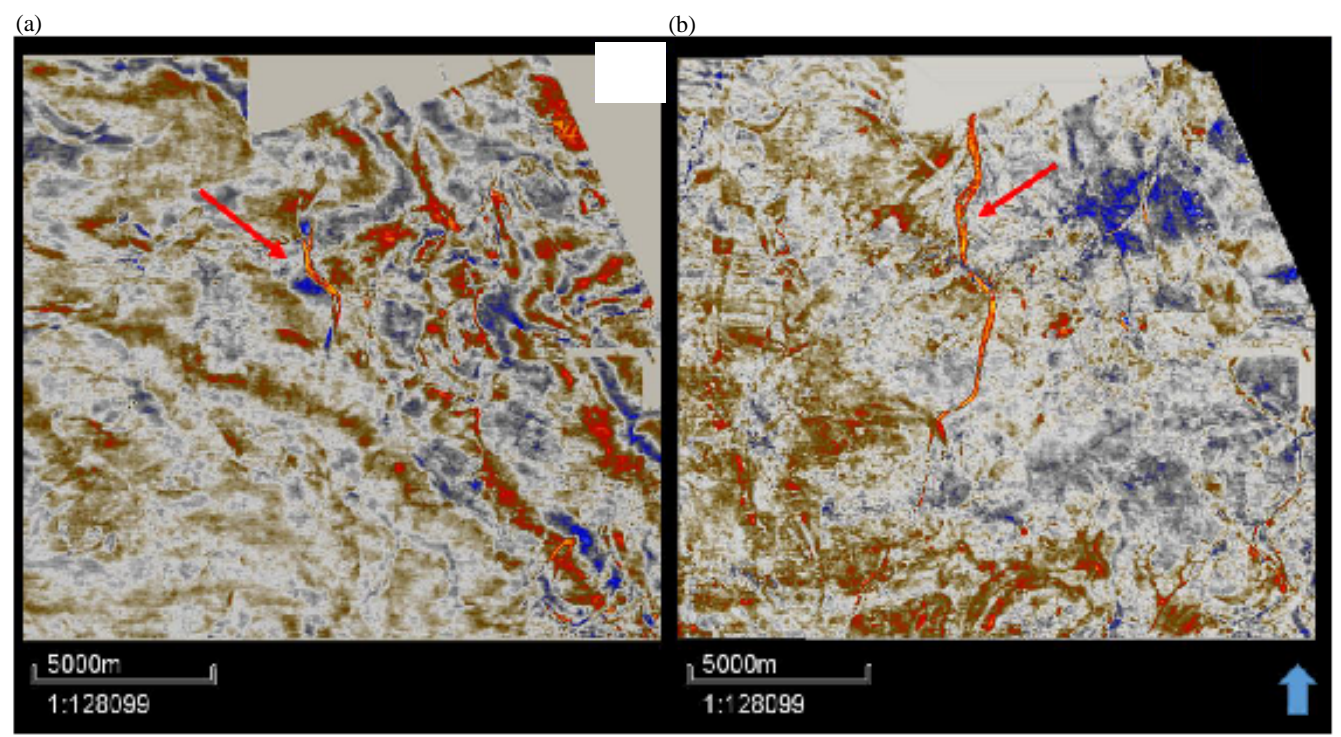

Fig. 5: Seismic response at bottom F, -964 msec; a) Horizontal planar slice-time slice and b) Horizontal parallel slice-horizontal slice

is satisfactory because of good seismic orientation during seismic survey. However, it is difficult to recognise channel patterns, channel pathways and also depositional elements through seismic section only.

\section{Horizon slices and attribute}

Analysis: Results from time slices are not that accurate as time slices represent horizontal slices from the volume cubes and are not parallel to seismic reflection. Meanwhile, horizon slices display the reflection amplitude pattern which indicate the presence of depositional environment such as fluvial and point bars. Both time slices and horizon slices are in map view which allows the interpreter to analyse depositional environment throughout the whole study area. For this case, several time slices/horizon slices have been interpreted at Bottom F, Top H, Middle H, Low H, Top I, I-50 and I-60. From time slices, it is proven that geomorphological features in the field area especially, channel systems starting from slices at TWT $-964 \mathrm{msec}$ (Bottom F) downwards. A major channel pattern can clearly defined, especially in Group I.

At Bottom $\mathrm{F}$, only one small anomaly can be identified at upper part as shown in Fig. 5. The anomaly is outlined with high amplitude value might indicate thin, straight and isolated channels. However, no element structure can be observed from time slices. Oxbow Lake or meander pattern can be identified at bottom part of horizon slices. It is difficult to interpret depositional environment through seismic slices as nothing much is seen. As Group $\mathrm{F}$ is interpreted as coastal fluvial plain deposit, it might be dominated by low energy mud or fine sediment.

Figure 6 shows results of horizontal planar slice and horizontal parallel slice at $-1304 \mathrm{msec}$. A huge contrast can be observed in both diagrams; high amplitude on the top right of time slices (Fig. 6a) but no significant geomorphology indicator. However, in the centre of horizon slices (Fig. 6b), there is a fluvial deposit with meander pattern flow from north-west to south-east as indicated by the red arrow. The channel flow patterns are complex at the central part and there are numerous disjointed channel sections especially at the bottom area. Other depositional elements might be observed such as point bar, crevasse splay, flood plain and inter-channel deposits.

Attribute analysis enhances stratigraphic features at the area of interest. Variance, sweetness and instantaneous frequency have been done in order to give better results in channel pathways, reflection strength, lithology formation and hydrocarbon prediction.

Figure 7 shows the result of sweetness attribute. A high amplitude is clearly seen in Fig. 7a throughout the channel and at Fig. $7 \mathrm{~b}$ high amplitude response at the edge of meandering and also at point bar indicate by arrows. The reflection strength indicate a huge changes in reflection coefficient in the lithology. Whereas Figure 8 show continuity of the channel. The resolution of the channel in Fig. 8a is clear as only a single channel can be observed. Meanwhile, in Fig. $8 \mathrm{~b}$ a fine meander stacking is observed at the center of the surface. The 
(a)

(b)

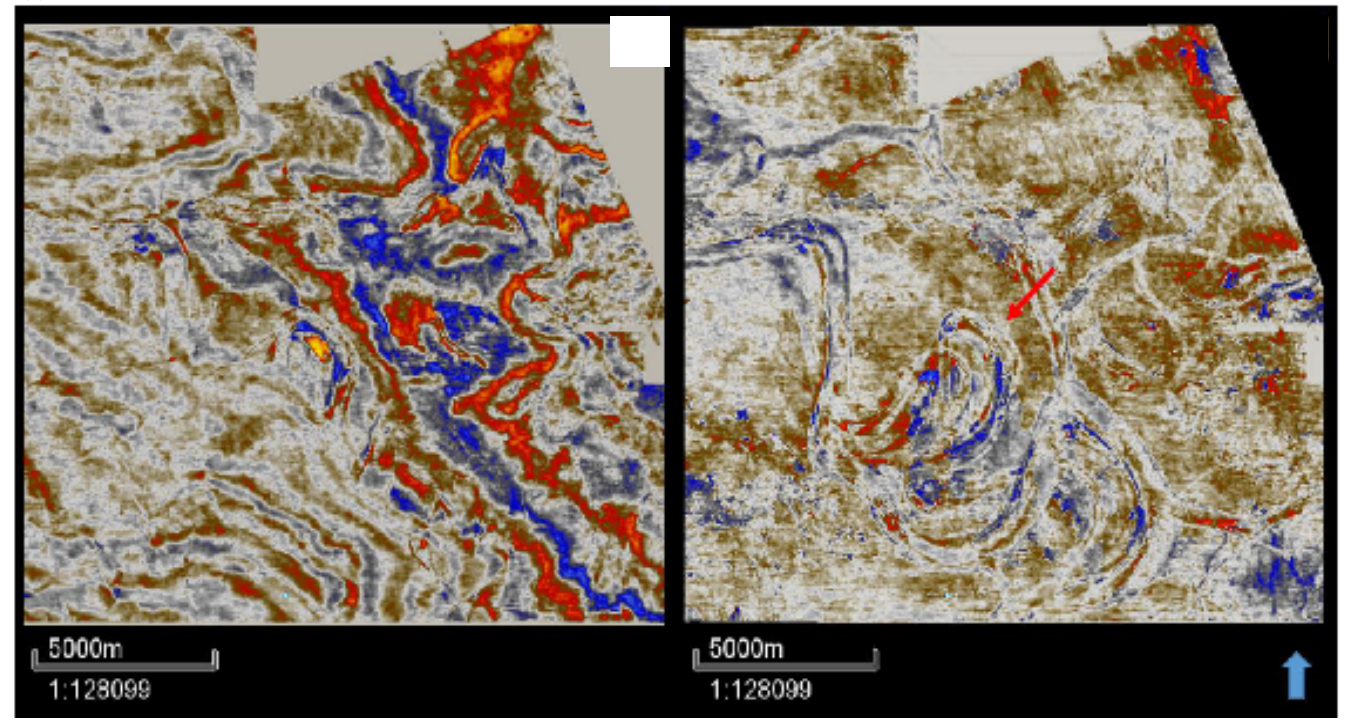

Fig. 6: Seismic response at I-50, -1304 msec; a) Horizontal planar slice-time slice and b) Horizontal parallel slice-horizontal slice

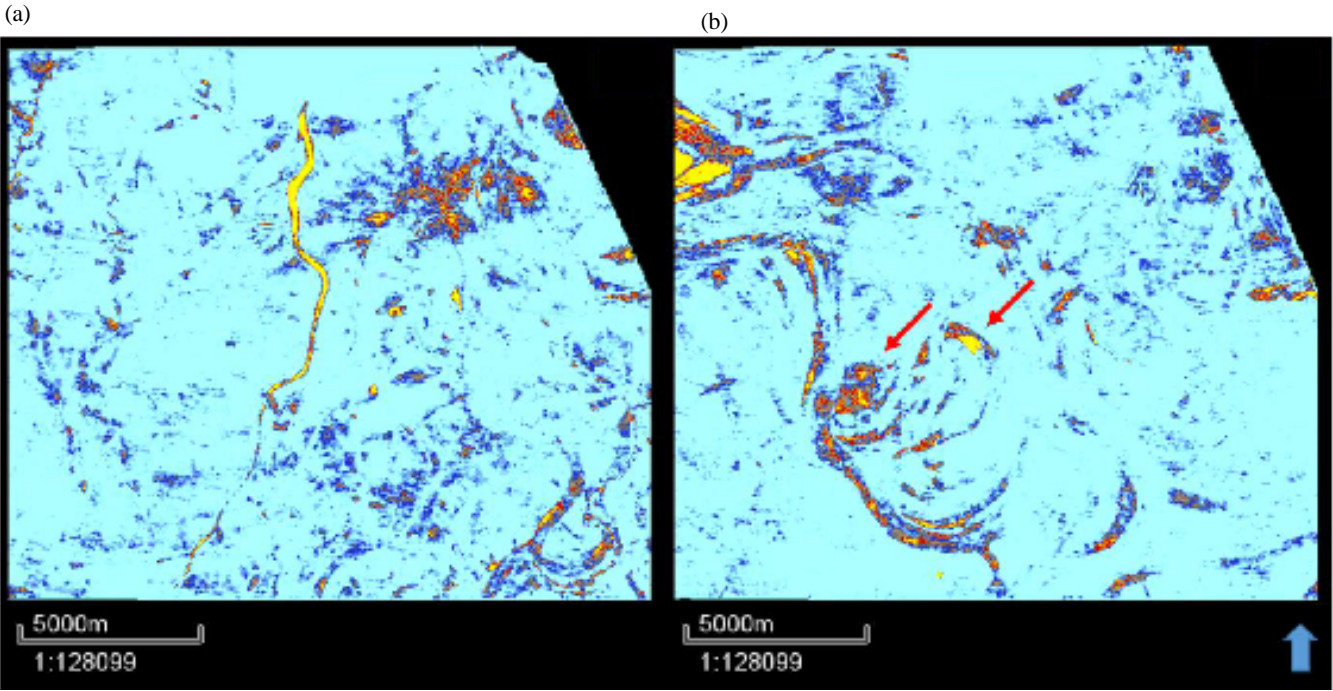

Fig. 7: Sweetness attribute analysis; a) Surface map bottom F and b) Surface map I-50

channel top and bottom can be observed from $-1285 \mathrm{msec}$ till-1330 msec TWT. Since, this channel is bigger in size hence the channel edge can be identified clearly at dominant frequency $31.25 \mathrm{~Hz}$.

In multi-attribute (Fig. 9a), channel path can be seen clearly with low frequency. High amplitude with low frequency might show hydrocarbon potential fill inside the channel. Figure $9 \mathrm{~b}$ shows low frequency especially at meanders and point bars. A clear channel stack can be observed from $-1,280 \mathrm{msec}$ till $-1,330$ msec stacking towards NE. Stacking channel allow more sediment to deposit, hence, it has potential for hydrocarbon to accumulate. Frequency colour changes drastically at bottom left corner, indicates different depositional environments. Figure 10 shows the seismic section across the point bar area. Top of point bar can be easily recognized indicated by negative amplitude value interbedded with thin sandstone. However, the amplitude changes of sands is not as bright as that on the edge of point bar. Hence, it is difficult to proof that the point bar filled with hydrocarbon. 


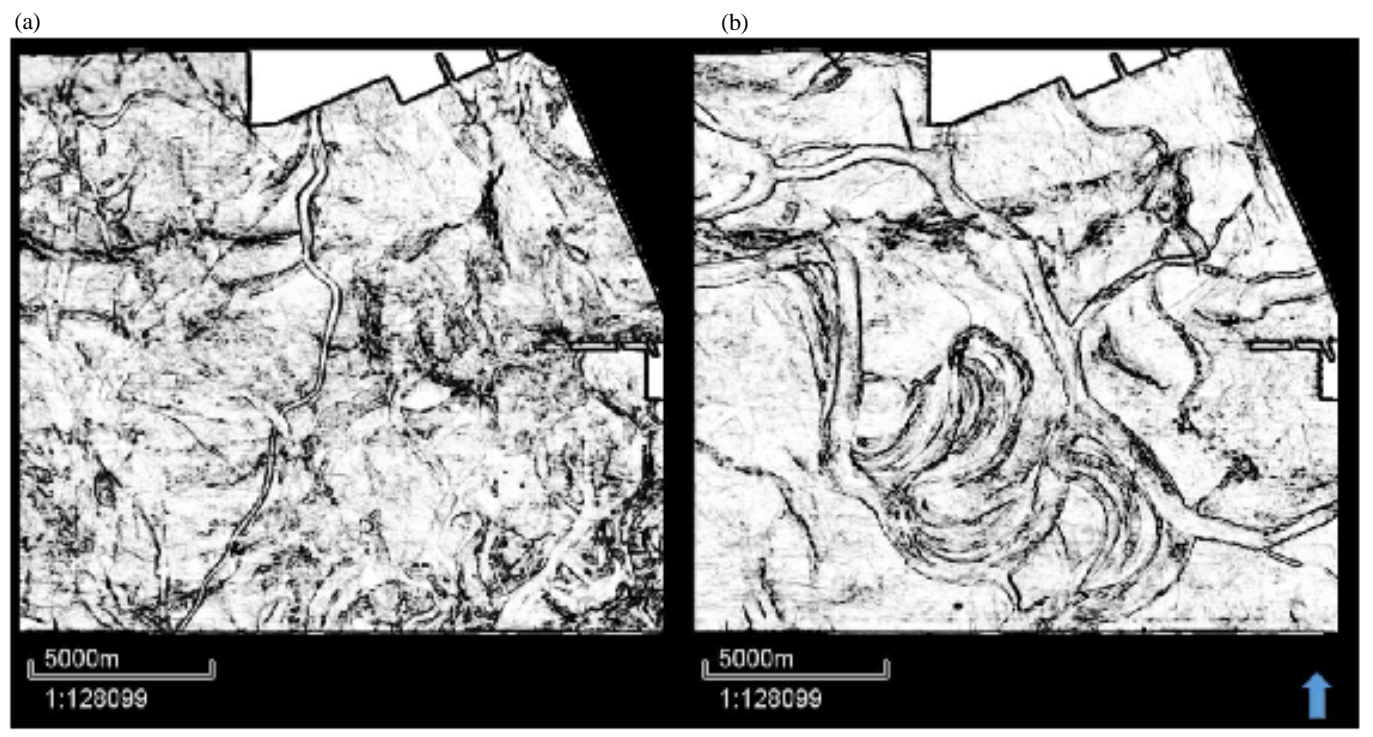

Fig. 8: Variance attribute analysis; a) Surface map bottom F and b) Surface map I-50

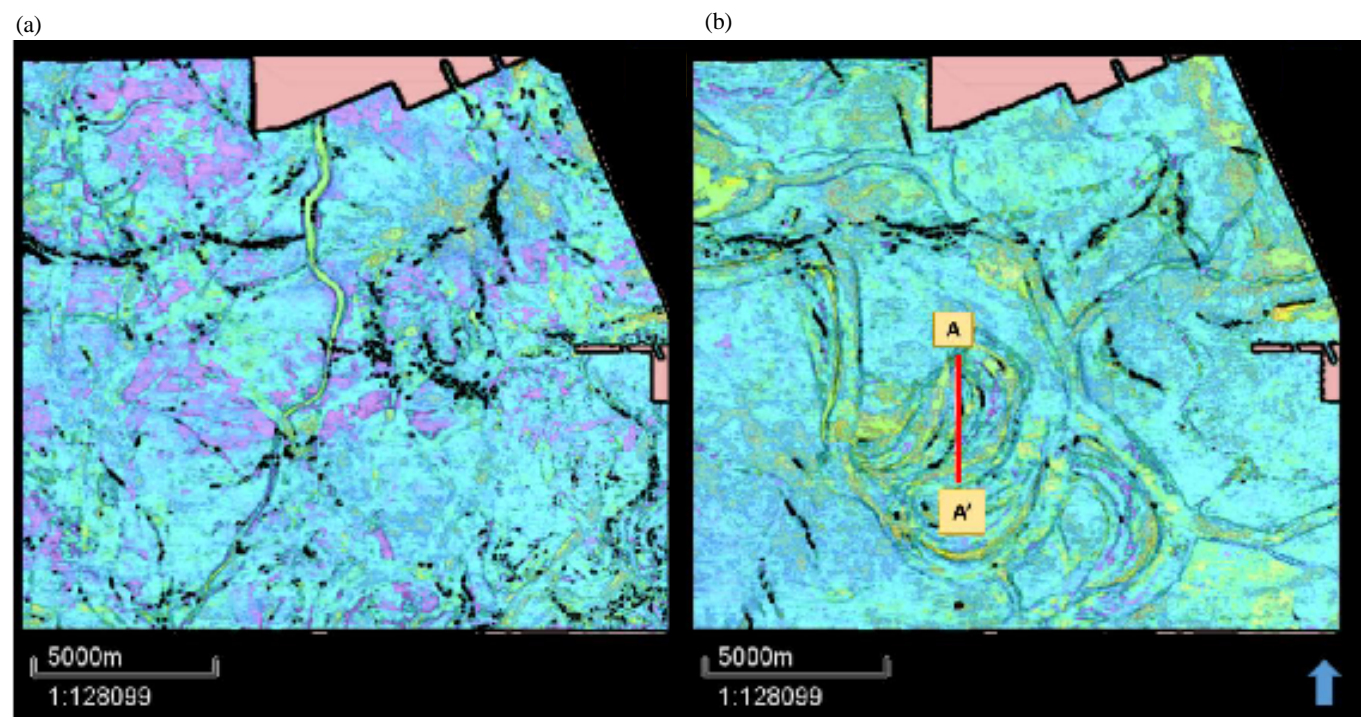

Fig. 9: Multi-attribute analysis; a) Surface map Bottom F and b) Surface map I-50

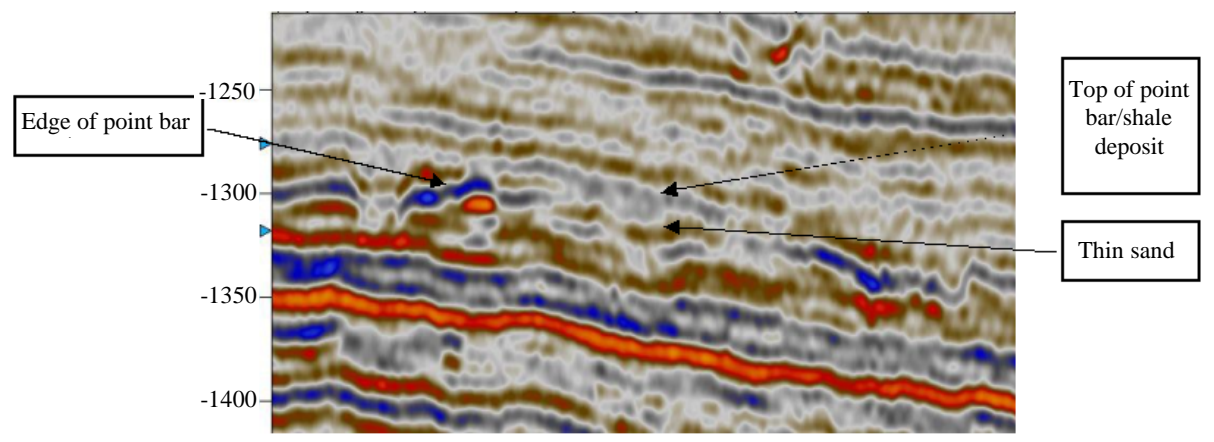

Fig. 10: Seismic section A-A' of Fig. 9b at X-line 4324 shows indication of edge of point bar and meander channel 


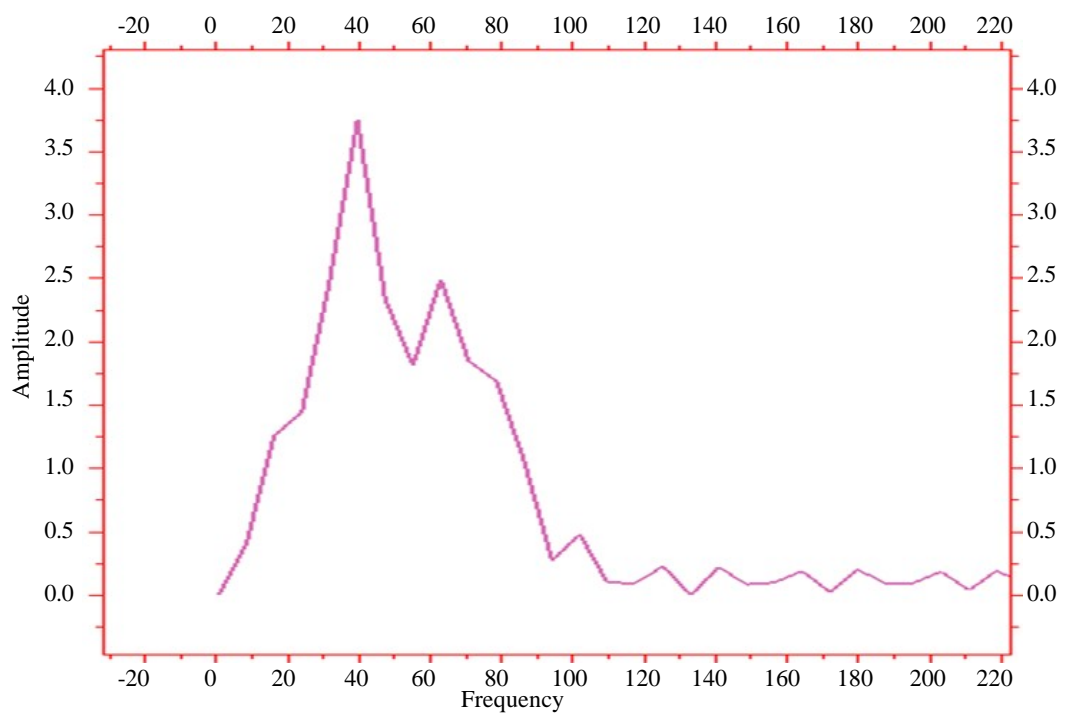

Fig. 11: Amplitude spectrum at X-line 4337 depth of $500-1500 \mathrm{msec}$ with dominant frequency is $39.06 \mathrm{~Hz}$

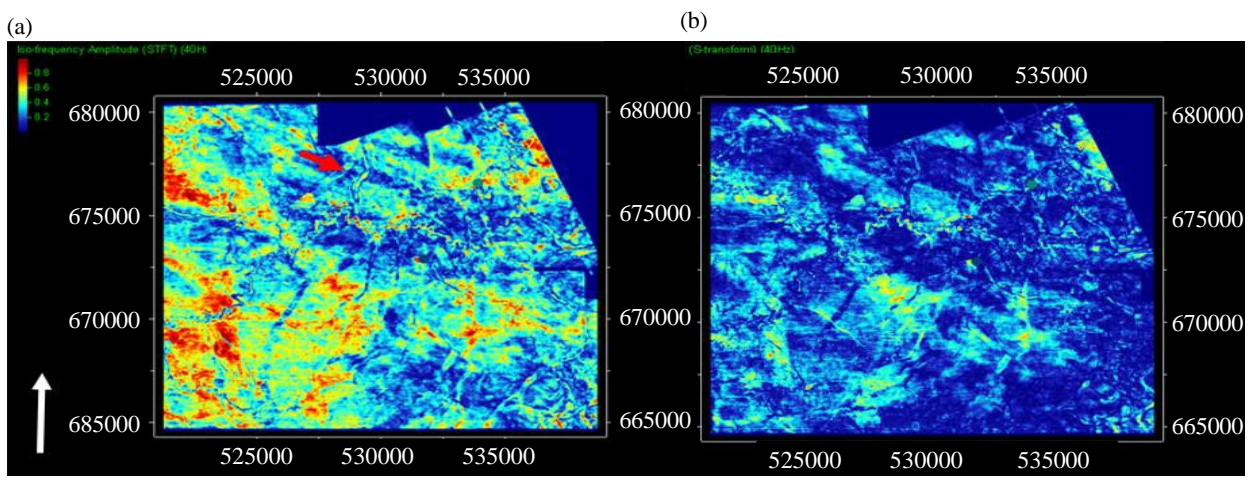

Fig. 12: Surface map of spectral decomposition $40 \mathrm{~Hz}$ at time slices -964 msec; Bottom F; a) STFT and b) S-transform

Spectral decomposition: Spectral decomposition was performed in order to get a better resolution of channel distribution. After determining the target zones, spectral decomposition was applied. Two methods were used, S-transform and Short Time Fourier Transform (STFT). S-transform give a good frequency resolution. Meanwhile, STFT focuses on time (temporal) resolution. Dominant frequency was placed at $31.25 \mathrm{~Hz}$ and it is difficult to recognize thin geomorphology at low frequency. Furthermore, different depth level will give different frequency response. STFT is the traditional approach in spectral decomposition which the size of the window is fixed once given. Whereas S-transform the size of the moving window will change determined by frequency.

At X-line 4337, the amplitude spectrum was obtained as shown in Fig. 11. A range of frequency bandwidth with dominant frequency of $39.06 \mathrm{~Hz}$ was determined from the results of amplitude spectrum.
The frequency values obtained based on the amplitude spectrum is shown in Fig. 11 is equal to 18, 39, 55,62 and $77 \mathrm{~Hz}$. The value is determine based on frequency tuning. Variation of frequency value is needed because high frequency will result in high resolution. Hence, it gives more information about the geological structures.

Spectral decomposition slices for the STFT and S-transform are shown in Fig. 12a, b, respectively. By comparing the time slices, STFT give a better delineation of the channel compared to S-transform. In this scenario, at $40 \mathrm{~Hz}$ STFT is able to outline subtle geological features such as small tributaries as indicate by red arrows. Meanwhile, for S-transform, the channel itself looks blurry. Therefore, the boundary of the channel can be recognized through implementation of STFT, since, it gives better temporal resolution compared to S-transform. 
(a)

(b)

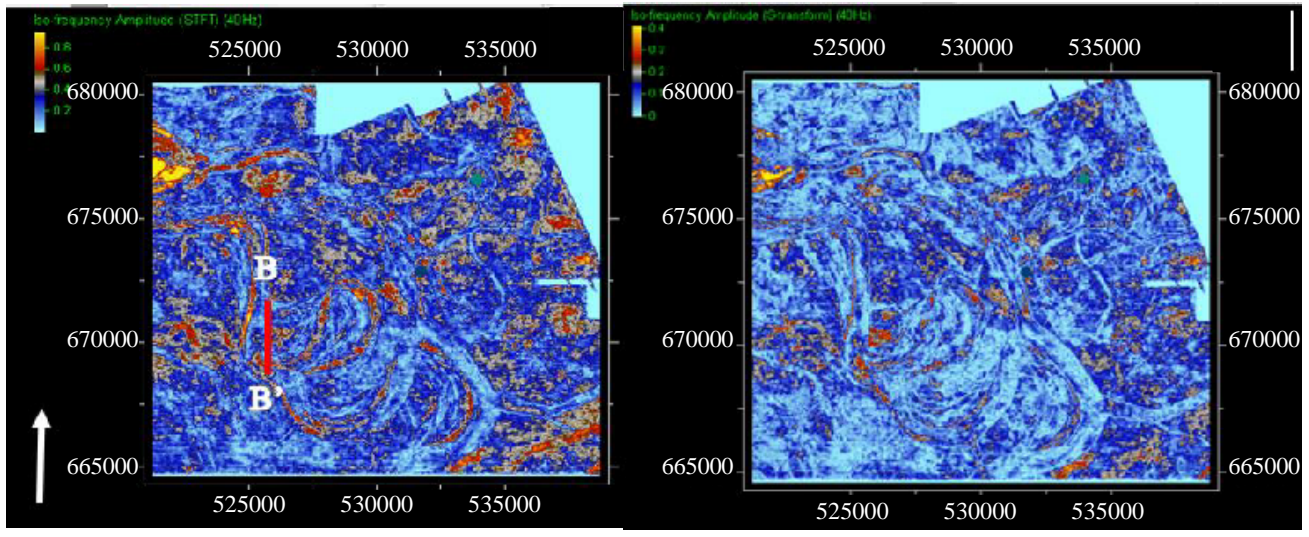

Fig. 13: Surface map of spectral decomposition $40 \mathrm{~Hz}$ at time slices $-1.304 \mathrm{msec}$; a I-50; a) STFT and b) S-transform

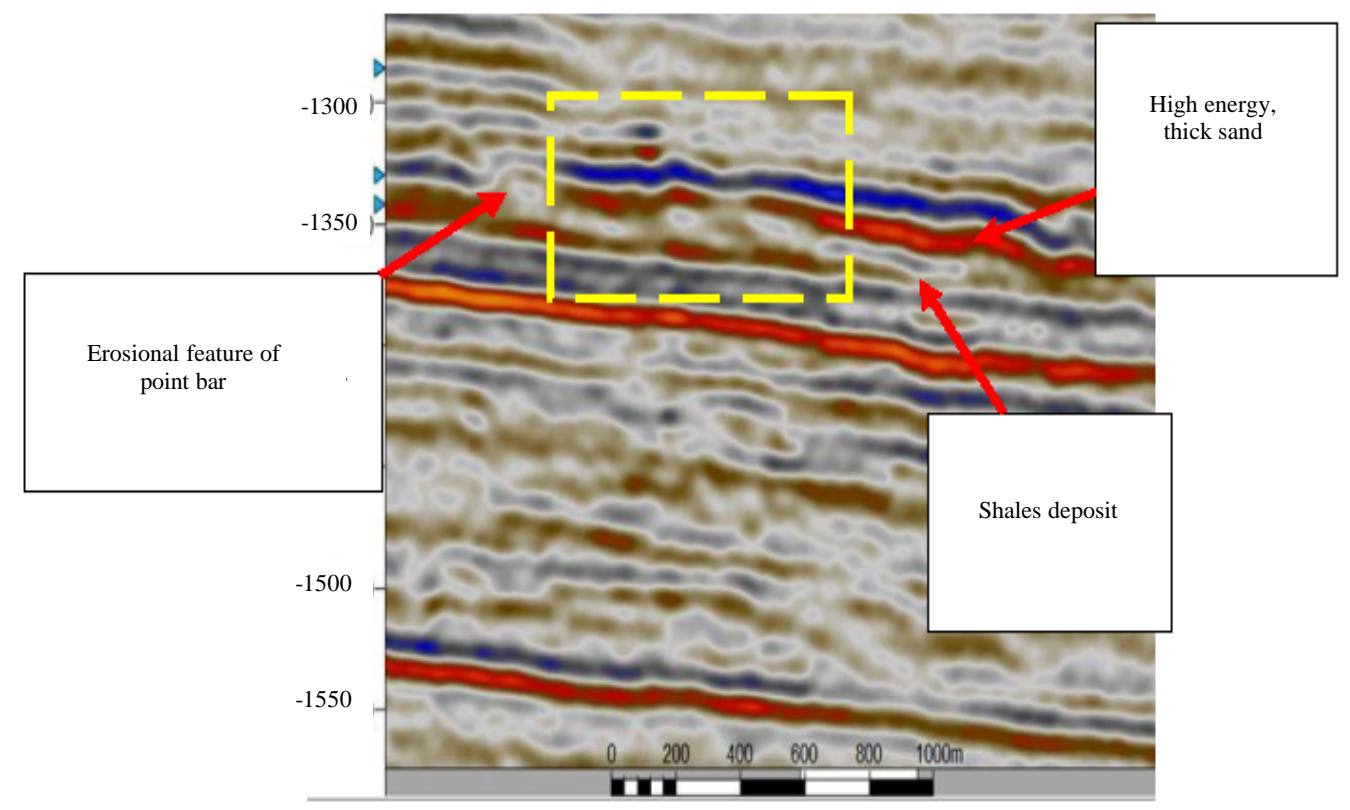

Fig. 14: Seismic section B-B' of Fig. 13b. The single point bar is marked by yellow rectangles

The seismic section, Fig. 14 shows the erosional features of a single point bar (moderate amplitude with discontinuous reflection) as marked by the red arrow. Since, the meander has high sinuosity, the energy flow decreases (at meander area) and allows sand to deposit as point bars. Sea level changes the point bar to be filled with shale and sand (heterogeneities). However, high amplitudes can be identified as top of point bar. This point bar has potential to be a stratigraphic hydrocarbon trap.

RGB colour blend map was generated at I-50 focusing alongside channel areas using a time window of $1285-1330 \mathrm{msec}$ as shown in Fig. 15. There are several point-bar sandstone bodies. Some of them may be filled with hydrocarbon within the interpreted meander belt indicated in blue. Based on RGB map, the meander belt seems to cross/cut and form an oxbow lake. However, meander channel stack cannot be observed. In addition, the A-2 well penetrated narrow straight channels; there are indications of thin sandstone that filled the channels and a thick seal deposited at the top of channel sandstone bodies as shown by Gamma ray log in Fig. 16.

Since, a thin sandstone can be identified at level I-50 at A-2 well; there is also a possibility of hydrocarbon accumulation in the meander belt and point bars. Figure 17 shows a significant anomalies with high amplitudes proven as a meander belts, edge of the channel and point bars. 


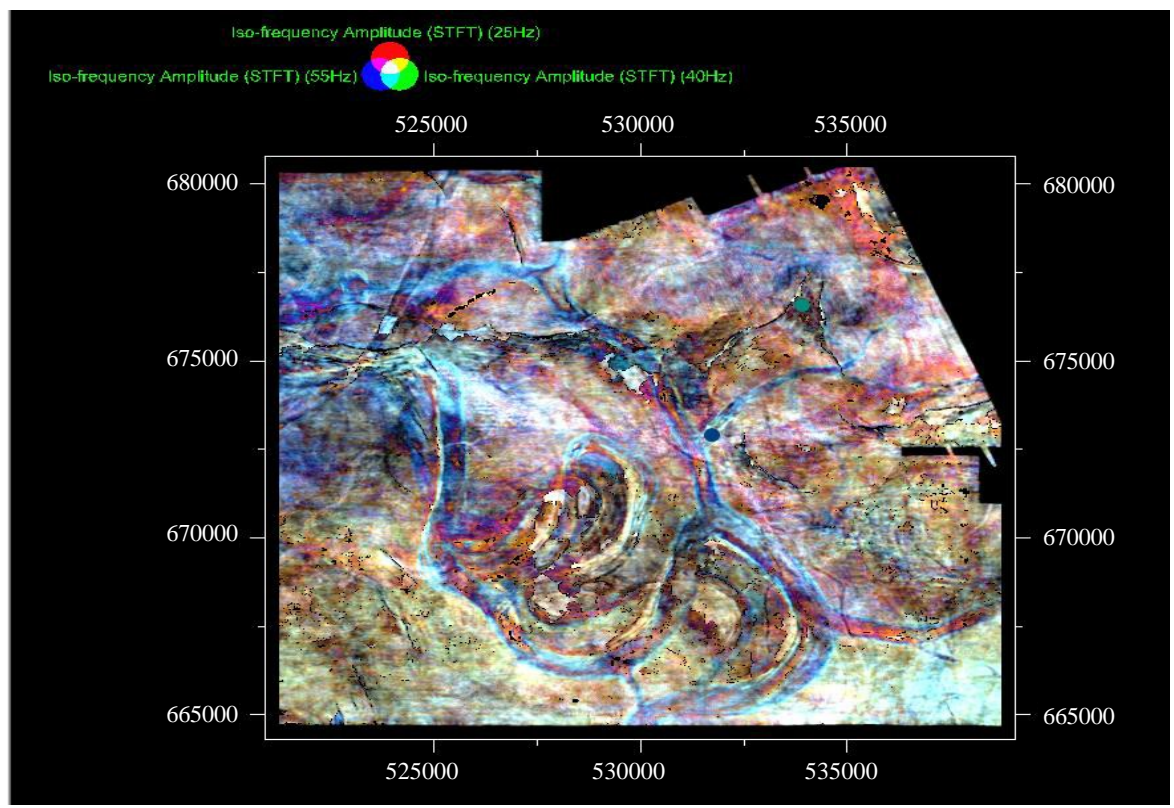

Fig. 15: RGB blend of spectral component of 25,40 and $55 \mathrm{~Hz}$. A huge clear meandering channel is observed throughout I-50 interval. High sinuosity of meander led to formation of point bar and cut-off oxbow lake. The meander channels are filled with different colour from surrounding showing variation of formation (heterogeneity) which reflects variation in transportation energy level

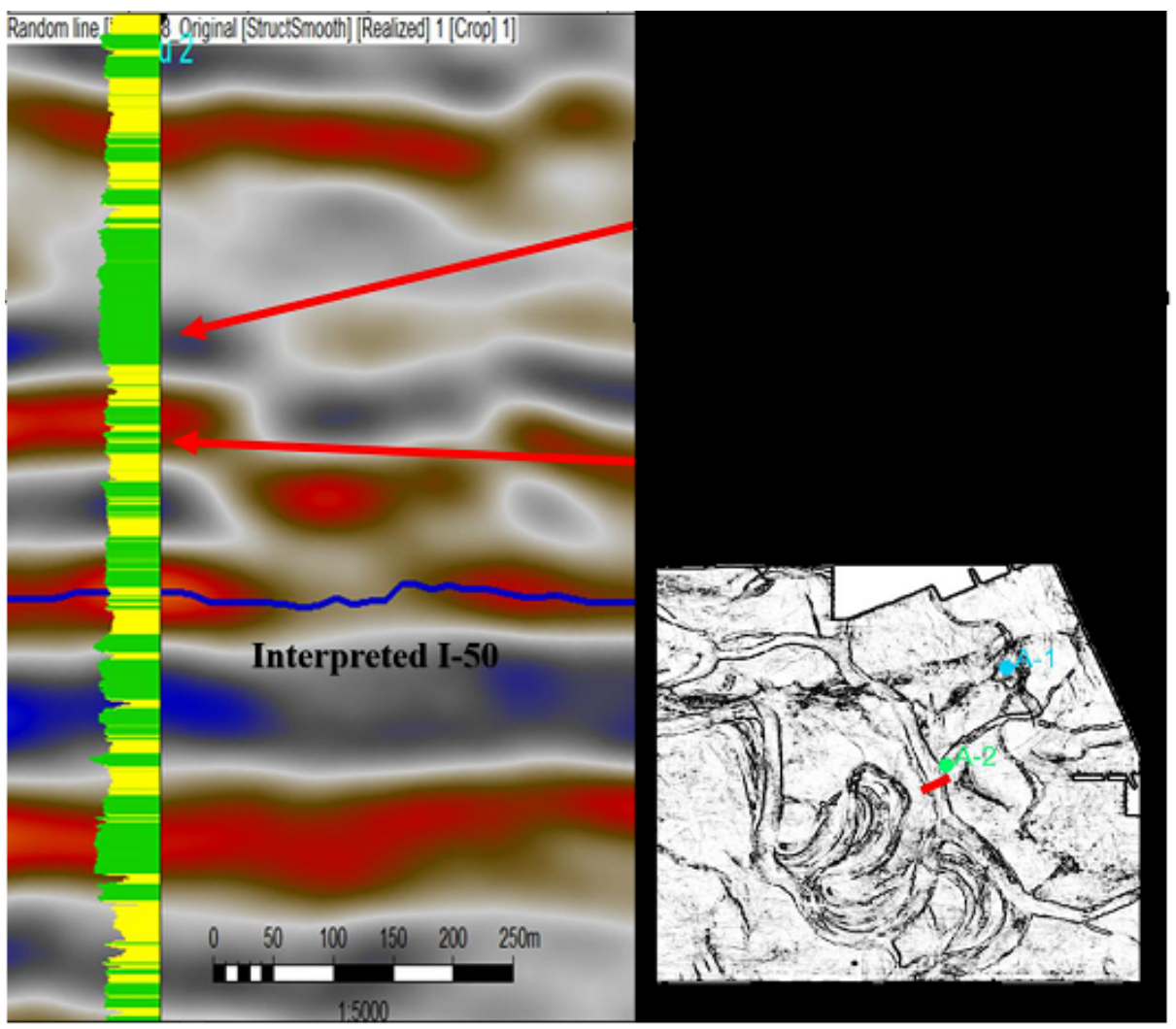

Fig. 16: Cross section at composite line with Gamma ray log where A-2 penetrated the channel 


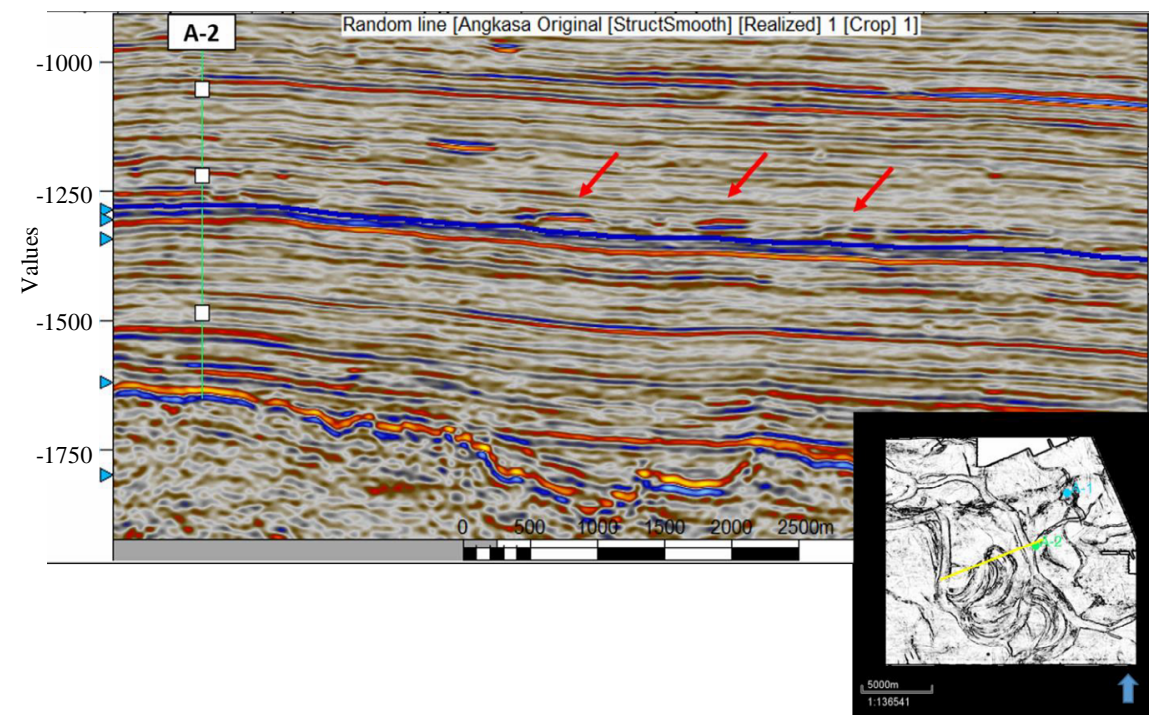

Fig. 17:3 channels seismic pattern with strong amplitude identified at I-50 horizon and has potential of stratigraphic reservoir

\section{CONCLUSION}

Most of the exploration geologist focus on structural traps rather than stratigraphic traps in Malay Basin. Advancement mode in exploration technology leads to recognition of geomorphology even at deeper depth. Several channels are identified in Group F, H and I. However, in this paper only two significant channels are studied in detail. Since, there is no exploration well penetration inside the channel area, hydrocarbon prediction can only be based on attribute analysis and spectral decomposition. A straight narrow channel has been identified at $\mathrm{F}$ Bottom.

Based on attribute analysis, the channel shows high amplitude response even at low frequency. After increasing frequency bandwidth up to $50 \mathrm{~Hz}$, several distributaries can be seen clearly which indicates the channel was at transitional zone between fluvial coastal environment and shallow marine. Meanwhile, at I-50, a large meander channel can be identified. There are two target areas with hydrocarbon potential located at point bar and meander belt. STFT and S-transform is a good method to extract subtle geological features. STFT is useful to identify thickness of hydrocarbon pay as it is good in vertical resolution. Meanwhile, S-transform results in better frequency resolution. Much information can be identified by RGB colour blend. However, the result is not as expected. Hence, it is difficult to interpret through RGB method. Generally, spectral decomposition method has identified potential hydrocarbon bearing sands at deeper part of the reservoir zone. In addition, combination of variance, instantaneous frequency and sweetness increase confidence level of hydrocarbon potential.

\section{ACKNOWLEDGEMENTS}

I extend my appreciation to my supervisor AP Lo Shyh Zung for his guidance and helpful discussion. I would like to thank to Universiti Teknologi petronas and petronas for giving opportunity for doing my research study and provide 3D seismic data at block PM318.

\section{REFERENCES}

Partyka, G., J. Gridley and J. Lopez, 1999. Interpretational applications of spectral decomposition in reservoir characterization. Leading Edge, 18: 353-360.

Sinha, S.K., P.S. Routh, P.D. Anno and J.P. Castagna, 2003. Time-frequency attribute of seismic data using continuous wavelet transform. Proceedings of the 74th Annual International Meeting on Society of Exploration Geophysicists, October 26-31, 2003, SEG, Dallas, Texas, pp: 1481-1484.

Sulaiman, N., U. Hamzah and A.R. Samsudin, 2016. Facies analysis and stratigraphic sequence of the North East Malay basin, Offshore terengganu, Malaysia. ARPN. J. Eng. Appl. Sci., 11: 2849-2858.

Thinh, N.T., 2014. Paleo-depositional environment reconstruction of Oligocene, early Miocene intervals in Northeast part of Malay Basin. Bull. Earth Sci. Thailand, 3: 52-54.

Tjia, H.D., 1994. Inversion tectonics in the Malay Basin: Evidence and timing of events. Geol. Soc. Malaysia Bull., 36: 119-126. 